\title{
Dinâmica e Transição da Incerteza no Brasil: uma investiga- ção de autorregressão quantílica
}

\author{
Michel Cândido de Souza ${ }^{1}$ \\ Udilmar Carlos Zabot ${ }^{2}$ \\ Sidney Martins Caetano ${ }^{3}$
}

\section{Resumo}

Recentemente, o número de estudos sobre incerteza na economia tem aumentado, em parte, devido às novas técnicas que permitem a construção de proxies adequadas para a incerteza, fundamentalmente não observável, com destaque à técnica de webscrapping, que permite extrair informações online e atualizadas, e que tem sido frequentemente utilizada na construção desses indicadores. Neste contexto, a partir de dois indicadores de incerteza, investiga-se a dinâmica e transição da incerteza no Brasil usando representações autorregressivas quantílicas. Os resultados revelam uma dinâmica assimétrica ao longo de diferentes quantis condicionais, corroborados pela análise de dispersão, amplitude e densidades. Ainda, sugere-se existência de baixa probabilidade, ou até mesmo nula, de migrar-se de um estado de alta incerteza para níveis baixos e vice-versa.

\section{Palavras-Chave}

Incerteza. Regressão quantílica. Assimetria.

\footnotetext{
Abstract

Recently, the number of studies about economic uncertainty has increased, in part due to the new techniques that allow the construction of appropriate proxies for uncertainty, fundamentally unobservable, specially the web-scrapping technique that allows to extract updated online information, and which has been frequently used in the construction of these indicators. Based on two of this uncertainty indicators, we investigate the dynamics and transition of uncertainty

- Os autores gostariam de deixar agradecimentos aos pareceristas por todas as considerações e ao CNPq, CAPES e FAPEMIG pelo suporte financeiro.

1 Professor - Universidade Federal dos Vales do Jequitinhonha e Mucuri (UFVJM).

Endereço: Rua Cruzeiro, 1 - Jardim São Paulo - Teófilo Otoni - Minas Gerais/MG - Brasil. CEP: 39803-371 - E-mail: michel.souza@ufvjm.edu.br - ORCiD: https://orcid.org/0000-0002-9732-7223.

2 Professor - Universidade do Estado de Mato Grosso (UNEMAT) - Endereço: Avenida dos Ingás, 3001 - Jardim Imperial - Sinop - Mato Grosso/MT - Brasil - CEP: 78556-252 E-mail: udi.zabot@unemat-net.br _ ORCiD: https://orcid.org/0000-0002-8482-1804.

3 Professor - Universidade Federal de Juiz de Fora (UFJF) - Endereço: Campus Universitário, s/n, Martelos - Juiz de Fora - Minas Gerais/MG - Brasil - CEP: 36036-900.

E-mail:sidney.caetano@ufjf.edu.br - ORCiD: https://orcid.org/0000-0002-2196-2095.

Recebido: 25/09/2017. Aceite: 15/10/2018.
}

(c) (i) (\$) Esta obra está licenciada com uma Licença Creative Commons Atribuição-Não Comercial 4.0 Internacional. 
in Brazil using quantitative autoregressive representations. The results reveal asymmetric dynamic along different conditional quantiles, corroborated by the analysis of dispersion, amplitude and densities. Furthermore, it is suggested that there is a low or even null probability of migration from a high uncertainty condition to a low level and vice versa.

\section{Keywords}

Uncertainty. Quantile regression. Asymmetry.

\section{JEL Classification}

C22. E00.

\section{Introdução}

A análise dos efeitos da incerteza sobre a economia real tem recebido destaque na literatura econômica recente. Conforme ressaltam Denis e Kannan (2013), embora os efeitos da incerteza na atividade econômica já tenham sido destacados (ver Bernanke (1983), Romer (1990), Dixit e Pindyck (1994)), os eventos recentes que afetaram a economia mundial induziram maior interesse sobre esta questão. No que se seguiu ao trabalho de Bloom (2009), em particular, os efeitos da incerteza sobre as flutuações macroeconômicas têm sido um tema recorrente nas discussões acadêmicas, entre os formuladores de política econômica e no âmbito do mercado financeiro. Incerteza pode ser entendida como uma situação na qual, para um dado conjunto de ações, as possibilidades de que determinados resultados ocorram é desconhecida, ou seja, diversos cenários são possíveis a partir da situação inicial, embora não seja possível estimar as probabilidades de que cada um ocorra. No caso em que estas probabilidades são conhecidas, trata-se tão somente de risco.

De acordo com Bernanke (1983), choques de incerteza têm efeitos significativos sobre a tomada de decisões dos agentes econômicos, principalmente quando há algum grau de irreversibilidade associado a esta decisão, influenciando, assim, diretamente as oscilações dos ciclos econômicos. Ademais, Bloom et al. (2013) sugerem que o grau de incerteza econômica está, aparentemente, relacionado à profundidade de recessões e à capacidade de recuperação subsequente, o que, segundo Aastveit et al. (2013), implica uma menor resposta às ações de política econômica em períodos de elevada incerteza, e oferece maiores desafios aos formuladores de 
política. Em um comunicado recente, por exemplo, o Banco Central do Brasil destacou a preocupação com o nível de incerteza na economia brasileira, ao ressaltar que "[A] manutenção, por tempo prolongado, de níveis de incerteza elevados sobre a evolução do processo de reformas e ajustes na economia pode ter impacto negativo sobre a atividade econômica". ${ }^{1} \mathrm{O}$ comunicado ainda deixa claro que as projeções condicionais do Copom para aquele momento envolviam maior grau de incerteza.

Nota-se, portanto, uma crescente preocupação com os efeitos da incerteza sobre a economia real, em que se pode destacar Bloom (2009), Bachmann et al. (2013), Gilchrist et al. (2014), Leduc e Liu (2016), entre outros. Entretanto, conforme argumentam Caggiano et al. (2014) e Jurado et al. (2015), o nível de incerteza normalmente é maior durante os períodos de recessão, ou seja, a incerteza apresenta uma dinâmica assimétrica entre as diferentes fases do ciclo econômico, o que sugere a necessidade de modelos não lineares na análise dos efeitos da incerteza sobre a economia real.

Para a economia brasileira, em particular, ainda é bastante restrito o número de trabalhos que se dedicam a investigar as características e os efeitos da incerteza econômica. Costa Filho (2014), por exemplo, indica que choques positivos na incerteza produzem efeitos negativos e rápidos na economia, quando comparados com choques na taxa de juros. Contudo, após as eleições presidenciais de 2014, pode-se observar que a série de incerteza cresceu de forma significativa. Conforme mostram Ferreira et al. (2017), apesar da alta volatilidade do índice de incerteza (IIE-Br/FGV) prejudicar o reconhecimento da data de início da sua trajetória de crescimento a partir de 2014, é notória a mudança de patamar da incerteza brasileira nos últimos três anos.

Godeiro e Lima (2017), por sua vez, constroem índices de incerteza macroeconômica para o Brasil a partir de métodos econométricos, e observam períodos de recessão precedidos por um aumento da incerteza. Barboza e Zilberman (2018), usando diversas medidas de incerteza, mostraram mudanças no nível da incerteza afetando negativamente a produção industrial em cerca de $0,9 \%$ a $3,9 \%$.

1 Notas da 207a Reunião do Comitê de Política Monetária (Copom) do Banco Central do Brasil - 30 e 31 de Maio de 2017. 
De outra forma, pode-se dizer que o aumento recente da incerteza não foi apenas um choque pontual, mas uma expansão mais duradoura. Logo, uma questão interessante de investigação refere-se à possibilidade de os choques não serem simétricos. Ou seja, a persistência de choques de diferentes sinais e magnitudes podem ter impactos diferentes sobre a própria incerteza.

Diante disso, o presente trabalho busca contribuir analisando a dinâmica da incerteza no Brasil por meio do modelo autorregressivo quantílico (modelo QAR), proposto por Koenker e Xiao (2004), com o intuito de investigar a presença de assimetrias e persistências em diferentes quantis da série de incerteza. Oferece, portanto, uma contribuição diferente, uma vez que choques propostos, como em Costa Filho (2014) e Godeiro e Lima (2017), por meio de modelos de Vetores Autoregressivos (VAR), são aumentos únicos sobre o indicador, o que não permite verificar a assimetria da persistência presente na incerteza.

Inicialmente, por meio de testes de raiz unitária quantílico, investigam-se as características particulares de duas proxies de incerteza, divulgadas publicamente, referente à economia brasileira, a saber: i) Índice Economic Policy Uncertainty (EPU) proposto por Baker et al. (2016) para o Brasil; e ii) Indicador de Incerteza da Economia Brasil (IIE-Br) da Fundação Getúlio Vargas. Propõe-se aqui investigar se choques de sinais e magnitudes diferentes têm efeitos assimétricos na dinâmica da incerteza brasileira. Com isso, a assimetria na incerteza é diagnosticada de uma perspectiva de respostas a choques, pois este teste de raiz unitária permite detectar diferenças na persistência de choques. Em seguida, reforça a presença ou não da assimetria na incerteza utilizando-se da densidade condicional, de forma a discutir sobre a dispersão em diferentes momentos e as probabilidades de transição quantílicas que podem fornecer informações interessantes quanto às oscilações da incerteza, tanto em períodos de tensão quanto de calmaria na economia.

Os resultados apresentados visualmente, corroborados a posteriori pelos testes e análises, indicam uma dinâmica de incerteza com comportamento assimétrico nos diferentes quantis condicionais, isto é, seu comportamento depende da localização da incerteza na sua distribuição condicional. Esta importante característica da incerteza no Brasil não foi observada em estudos anteriores. 
Além da presente introdução, o trabalho está estruturado da seguinte maneira: a seção 2 elabora uma revisão da literatura recente relacionada à incerteza na economia; a seção 3 apresenta os dois indicadores de incerteza considerados no presente trabalho, bem como os aspectos metodológicos e os resultados empíricos; e a seção 4 mostra as considerações finais.

\section{Referencial Teórico e Empírico}

É crescente a literatura que procura avaliar os efeitos da incerteza sobre as condições macroeconômicas. Conforme destacam Popp e Zhang (2016), um aumento inesperado na incerteza tem efeito adverso sobre a economia real, principalmente durante períodos de recessão. Assim, vários estudos, considerando diferentes proxies para a incerteza, buscaram estimar os efeitos sobre a atividade econômica, sobre a demanda agregada, sobre o mercado financeiro ou, ainda, sobre a política econômica.

Em relação aos efeitos da incerteza sobre a oferta e demanda agregada, Bredin e Fountas (2007) apresentam resultados que indicam uma relação negativa entre a incerteza macroeconômica e o crescimento do produto. Ejarque (2009) sugere que, no contexto da Grande Depressão, um aumento na incerteza provocou um aumento nos gastos com bens duráveis e uma redução no investimento em capital físico, por serem estes mais irreversíveis. Denis e Kannan (2013), por sua vez, encontram evidências de impacto negativo de choques de incerteza sobre a produção industrial do Reino Unido, com efeitos semelhantes aos observados na economia americana.

Choudhry (2003) para os Estados Unidos e Menegatti (2010) para os países da OCDE investigam os efeitos da incerteza sobre o consumo, e ambos apresentam resultados que indicam efeitos significativos, indicando que um alto nível de incerteza reduz o consumo agregado. Já Raunig e Scharler (2011) estimam os efeitos da incerteza sobre as taxas de crescimento do consumo durável, consumo não durável e investimento privado para a economia americana, e seus resultados sugerem que a incerteza exerce efeito significativo e negativo sobre os componentes da demanda agregada, mas o efeito é maior sobre o investimento e relativamente menor sobre o consumo não durável. 
Gilchrist et al. (2014) consideram um modelo de equilíbrio geral no qual firmas heterogêneas se deparam com incerteza, irreversibilidade dos investimentos e fricções financeiras. Os autores constroem uma medida para a incerteza considerando dados de alta frequência do mercado de ações, que refletem mudanças exógenas na incerteza, e encontram evidências de que flutuações nesta última têm efeitos significativos sobre o investimento, e que este impacto ocorre através de mudanças nos spreads de crédito.

Em relação aos efeitos sobre os mercados financeiros, Bordo et al. (2016) apresentam resultados que indicam que a incerteza impacta negativamente o mercado de crédito e está associada ao baixo crescimento real da oferta de crédito bancário nos Estados Unidos nas últimas décadas. Esses autores destacam que essa relação contribui para a demora na recuperação da atividade econômica em períodos seguintes às recessões.

Liu e Zhang (2015) e Arouri et al. (2016), com base no índice proposto por Baker et al. (2016), apresentam evidências de efeitos negativos da incerteza de política econômica sobre a volatilidade e sobre o retorno do mercado de ações americano. Dakhlaoui e Aloui (2016), por sua vez, observaram que a incerteza na política econômica americana influencia a volatilidade nos mercados de ações dos países do bloco BRIC, principalmente em períodos de instabilidade econômica global. Bernal et al. (2016) avaliam o impacto da incerteza de política econômica sobre o spillover de risco na zona do Euro, e sugerem que a incerteza cria um ambiente favorável à transmissão de riscos oriundos de desequilíbrios fiscais sobre o mercado de títulos em toda a região.

Ainda com relação ao mercado financeiro, Bekiros et al. (2016) procuraram incorporar a incerteza em modelos de previsão de retorno de ativos e, a partir de regressões quantílicas, indicam que a incerteza tem um desempenho superior apenas nos quantis inferiores, quando comparado ao intercepto do quantil. Os autores observaram que o índice de incerteza de política econômica (EPU) contém informações fora da amostra significativas em torno da parte inferior para a mediana da distribuição do equity premium, embora não quando o comportamento de mercado é claramente otimista. 
Alguns estudos avaliaram os efeitos da incerteza sobre a condução e eficácia de política econômica. Considerando diferentes medidas de incerteza, Aastveit et al. (2013) demonstram que os choques de política monetária têm efeitos relativamente menores sobre a atividade econômica quando o nível de incerteza é elevado. Por sua vez, Istrefi e Piloiu (2015) sugerem que as expectativas de inflação são sensíveis a choques de incerteza, e as de longo prazo aumentam em resposta a estes choques. Ainda, Beckmann e Czudaj (2017) demonstram que as expectativas sobre a taxa de câmbio são afetadas não apenas pelos anúncios das autoridades monetária e fiscal, mas também pelo grau de incerteza relacionada à posição futura da política econômica, o que indica, segundo os autores, que os efeitos da incerteza não são incluídos eficientemente nas expectativas de mercado. Por fim, cabe destacar alguns estudos que investigam os efeitos da incerteza sob diferentes contextos macroeconômicos. Bloom et al. (2012) consideram choques de incerteza que direcionam os ciclos econômicos, e demonstram que a incerteza macroeconômica é anticíclica, aumentando em períodos de recessão. Considerando este último fato, Caggiano et al. (2014) isolam o impacto dos choques de incerteza sobre o desemprego em períodos de recessão na economia americana, e observam que os seus efeitos são substancialmente maiores nestas condições. Jurado et al. (2015) também apresentam resultados que sugerem que a incerteza macroeconômica é fortemente anticíclica, com efeitos maiores e mais persistentes em períodos de recessão.

Para a economia brasileira, em particular, a literatura é ainda restrita. Pereira (2001) considera um modelo de custos de ajustamento para analisar a relação entre incerteza e investimento. Como medida de incerteza, o autor considera a média das variâncias condicionais das séries de taxa de juros, taxa real de câmbio e preço de bens de capital, estimadas a partir de um modelo GARCH(1,1). Os resultados estimados para o período entre o primeiro trimestre de 1980, e o quarto trimestre de 1998, indicam que o investimento é negativamente afetado pela incerteza no longo prazo. Silva Filho (2007), por sua vez, avaliou a relação entre incerteza inflacionária e investimento para a economia no período entre 1974 e 2002, e encontrou fortes evidências de efeitos negativos sobre o investimento no país no curto e no longo prazos. 
Costa Filho (2014) considera três medidas de incerteza distintas, a saber: a variabilidade das expectativas de crescimento econômico; a variabilidade do mercado brasileiro de ações; e um índice construído com base na frequência da palavra 'incerteza' em alguns jornais. O autor estima efeitos negativos da incerteza sobre a produção industrial, sobre a confiança do consumidor, sobre as vendas no varejo e sobre o índice de atividade econômica do Banco Central (IBC-BR). Ainda, encontra evidências de que a incerteza eleva o desemprego.

Baseando-se em Scotti (2013), que mostram que medidas de previsão de analistas podem não ser eficientes, Godeiro e Lima (2017) constroem um índice de incerteza macroeconômica para o Brasil seguindo a metodologia proposta por Jurado et al. (2015). Seus resultados indicam que os períodos de recessão no país são precedidos pelo aumento no nível de incerteza e, ainda, apresentam evidências de uma correlação negativa entre a incerteza macroeconômica e produção industrial.

Finalmente, em um estudo mais recente, Barboza e Zilberman (2018) constroem um modelo SVAR seguindo Baker et al. (2016). Os autores diversificam a presença de medidas de incerteza e atividade econômica. Seus resultados mostram que os efeitos da incerteza sobre a atividade econômica são sempre negativos e significativos, em um horizonte médio de 6 meses.

De forma a contribuir com a literatura brasileira, em específico, a próxima seção busca investigar a dinâmica e transição da incerteza.

\section{Dinâmica, Persistência, Dispersão e Transição da Incerteza}

Conforme supracitado, os trabalhos apresentam diferentes proxies para a variável incerteza, por exemplo, utilizando alguma medida de volatilidade do mercado de ações, a variância das expectativas para alguma variável (crescimento, inflação, câmbio, etc.) ou algum indicador relacionado ao mercado financeiro. Contudo, recentemente, inúmeros estudos têm considerado como variável de incerteza o indicador proposto por Baker et al. (2016), que consiste em uma medida mais ampla de incerteza relacionada à condução de política econômica. 
O Índice Economic Policy Uncertainty (EPU) proposto por Baker et al. (2016), é baseado em três componentes distintos. O primeiro destes componentes quantifica a frequência e o volume de artigos dos principais jornais que discutem as questões de incerteza na política econômica. Um segundo componente reflete o número de disposições no código tributário federal previstas para expirar nos próximos anos. E um terceiro componente considera as diferenças entre as previsões dos analistas econômicos como proxy para a incerteza de mercado.

Os autores construíram esse índice de incerteza para vários países. Para o Brasil foram considerados arquivos apenas do jornal Folha de São Paulo para gerar uma série de incerteza desde 1991, conforme se pode ver na Figura la. Em cada mês, contou-se o número de artigos que continham os termos 'incerto' ou 'incerteza', 'econômico' ou 'economia', e um ou mais dos seguintes termos: regulação, déficit, orçamento, imposto, banco central, alvorada, planalto, congresso, senado, câmara dos deputados, legislação, lei, tarifa. Para obter o índice de incerteza, estimou-se o número relativo destes artigos dentre os artigos do jornal para o mesmo mês e, por fim, a série foi padronizada para uma média 100.

O Instituto Brasileiro de Economia (IBRE) da Fundação Getúlio Vargas também calcula e divulga o Indicador de Incerteza da Economia Brasil (IIE-Br), que considera o número de notícias sobre incerteza, a divergência nas expectativas e a volatilidade do mercado de ações. Especificamente, esse indicador é formado por três componentes distintos. O primeiro é o IIE-Br Mídia, baseado na frequência de artigos dos principais jornais ${ }^{2}$ do país que continham o termo 'economia' associado a pelo menos um dos termos 'incerteza', 'instabilidade' e 'crise'. O segundo é o IIE-Br Expectativa, baseado nas informações das séries de expectativas de mercado geradas pelo Banco Central do Brasil, e considera o coeficiente de variação das previsões 12 meses à frente para a inflação (medida pela variação percentual do Índice de Preços ao Consumidor Amplo-IPCA) e para a taxa de câmbio. O terceiro componente é o IIE-Br Mercado, baseado no mercado de ações e que considera a volatilidade da série de preços de fechamento diários do Ibovespa. Estas três medidas, em conjunto, minimizam os impactos que cada fator isoladamente pode ter no indicador final.

2 Para robustez e maior representatividade das diversas regiões do país, os autores utilizam seis jornais: Folha de São Paulo, Valor Econômico, O Globo, Estado de São Paulo, Correio Braziliense e Zero Hora. 
Assim, o Indicador de Incerteza da Economia Brasil é calculado de acordo com a seguinte ponderação:

$$
I I E B r t=0,7(\text { IIEBrtMídia })+0,2(\text { IIEBrtExpectativa })+0,1(\text { IIEBrtMercado })
$$

a) EPU/Baker et al. (2016) (1991:01 - 2017:03)

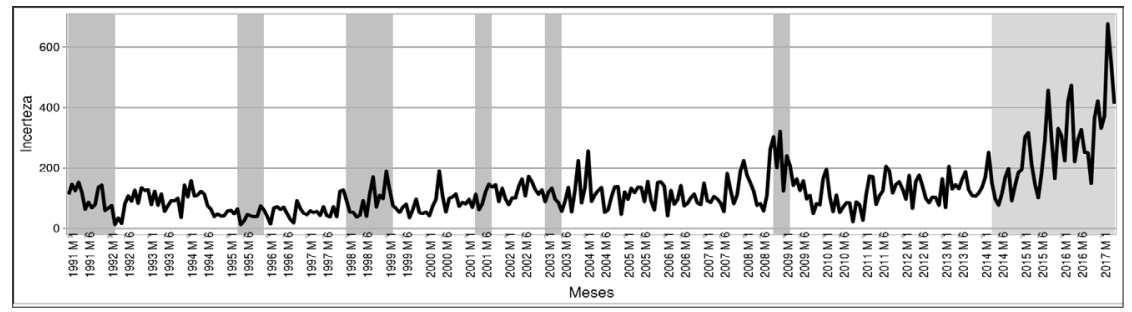

b) IIE-Br/FGV (2000:01 - 2017:06)

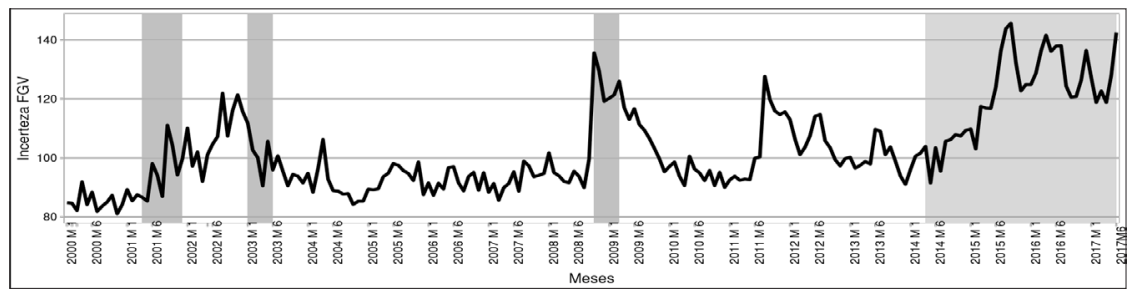

Figura 1 - Índices de Incertezas e Datação dos Ciclos Econômicos (CODACE)

O indicador final é padronizado tal que possui média 100 e desvio padrão 10 dentro da janela de referência. A série histórica do IIE-Br teve início em janeiro de 2000, conforme se pode ver na Figura 1b, e a coleta do Indicador de Incerteza da Economia é realizada do dia 26 do mês anterior ao de referência ao dia 25 do mês de referência.

As duas séries de incerteza apresentam uma correlação linear de 0,68, tornando, assim, relevante investigar a robustez dos resultados visuais. Entretanto, antes de apresentar a análise estatística, destaca-se, de forma breve, uma discussão da metodologia adotada nos exercícios empíricos. 


\subsection{Regressão Quantílica e Função Densidade}

Seja um quantil $\tau$ o valor $q$ tal que $100 \tau \%$ dos valores amostrais são inferiores a ele, de forma que $0<\tau<1$. A definição mais rigorosa pode ser enunciada utilizando-se a distribuição acumulada de uma variável aleatória $X$, em que $F(x)=P(X \leq x)$. Dessa forma, ao utilizar a função inversa da distribuição acumulada no ponto $\tau$, tem-se que o quantil de ordem $\tau$ da variável aleatória $X$ é $F^{-1}(\tau)=\inf \{x: F(x) \geq \tau\}$. Ou seja, a função distribuição acumulada inversa gera o valor do quantil para a probabilidade escolhida a partir do ínfimo dentre os que têm somatório probabilístico maior ou igual ao do quantil.

O método de Regressão Quantílica (QR) foi introduzido por Koenker e Bassett (1978). Permitindo, assim, estimar a relação entre um conjunto de variáveis explicativas, $x$, e o quantil de interesse, $\tau$, da variável dependente $y$. Tal método difere do modelo de Mínimos Quadrados Ordinários (MQO/OLS) que atuam somente sobre a média da distribuição da variável resposta. Tal abordagem tornou-se uma técnica útil, pois os efeitos de uma variável explicativa podem depender diretamente do tamanho da resposta, isto é, da localização de determinada observação na distribuição. A conclusão deste fato é que os modelos (QR) são capazes de incorporar uma possível heterocedasticidade, pois permitem verificar se o parâmetro de resposta das variáveis explicativas muda de forma significante (estatisticamente) para pontos diferentes da distribuição da variável dependente.

Considere um vetor de variáveis resposta contínuas e outro vetor da mesma variável defasada $x=\left(1, y_{t-1}, y_{t-2}, \ldots, y_{t-p}\right)$. Um modelo padrão de regressão linear é dado por $E(y \mid x)=x^{\prime} \beta$, sendo $\beta$ um vetor de $p+1$ parâmetros incluindo o intercepto. Já um modelo de autorregressão quantílica, $Q A R(p)$, pode ser compreendido como $Q_{y}(\tau \mid x)=x^{\prime} \beta(\tau)$, onde $\beta(\tau)$ é uma matriz de $p+1$ parâmetros por $\tau$ quantis. O quantil $\tau$ é fixo entre 0 e 1 e os parâmetros de regressão, por conseguinte, dependem de $\tau$ e representam os efeitos das variáveis dentro de $x$ sobre o $\tau$ quantil da distribuição de $y$. As estimativas de $\beta(\tau)$ são obtidas por meio da solução de:

$$
\min _{\forall \beta \in R} \sum_{i=1}^{t} \rho_{\tau}\left(y-x^{\prime} \beta(\tau)\right)
$$


Onde $\rho_{\tau}$ é uma função linear de perda, tal que:

$$
\rho_{\tau}(u)=\left\{\begin{array}{c}
\tau u, \quad u \geq 0 \\
(\tau-1) u, \quad u<0
\end{array}\right.
$$

Substituindo, tem-se que:

$$
Q(\beta(\tau))=\min \left[\tau \sum_{i: y \geq x^{\prime} \beta(\tau)}^{t}\left|y-x^{\prime} \beta(\tau)\right|+(1-\tau) \sum_{i: y<x^{\prime} \beta(\tau)}^{t}\left|y-x^{\prime} \beta(\tau)\right|\right]
$$

A função não diferenciável da Equação (4) requer métodos de programação linear para a sua minimização, sendo possível apresentá-lo por:

$$
\begin{gathered}
\min _{\beta(\tau) \in R} \tau U+(1-\tau) V \\
\text { s.a. } Y=\beta(\tau) X+U-V
\end{gathered}
$$

onde o vetor de erros $u$ é dividido nos vetores $U$ e $V$, com elementos que contêm, respectivamente, as partes positivas e negativas dos resíduos.

Algumas abordagens são comumente utilizadas na resolução, como o método Simplex para amostras com tamanho moderado ou o método de Pontos Interiores para bancos de dados maiores, ambos garantem uma solução por meio de um número finito de iterações. A construção dos intervalos de confiança acontece por meio das estimativas de erros padrão bootstrap, que são mais utilizados em relação aos erros padrão analíticos, mesmo nos casos em que os erros residuais são assintoticamente distribuídos de acordo com uma normal. A metodologia bootstrap é, em geral, preferível, pois não faz nenhuma suposição sobre a distribuição da variável resposta, sendo capaz de generalizar os resultados (QAR) e estimar os intervalos em qualquer caso de distribuição residual.

Em relação ao teste de raiz unitária, considerando a transformação de um processo autorregressivo baseado no teste Aumented Dickey Fuller, tem-se o seguinte modelo com drift e tendência:

$$
Q_{\tau}\left(y_{t} \mid y_{t-1, \ldots,} y_{t-q}\right)=\alpha(\tau) y_{t-1}+\mu(\tau)+\gamma(\tau) t+\sum_{i=1}^{q-1} \phi_{i}(\tau) \Delta y_{t-i}+\epsilon_{t}(6)
$$


Basicamente, pode-se estimar a Equação (6) em diferentes quantis, $\tau \in(0,1)$, obtendo um conjunto de coeficientes de persistência de $y_{t}$, tratados como $\alpha(\tau)=1$. Isso permite testar a hipótese nula em diferentes pontos da distribuição. Os resultados possibilitam verificar se os choques na série de incerteza têm magnitudes diferentes, bem como são persistentes ou transitórios. Por exemplo, $\alpha(\tau)=1$ implica a presença de raiz unitária e choques de efeitos permanentes. A rejeição da hipótese nula, $\alpha(\tau)<1$, mostra tendência estacionária e choques de efeitos temporários.

Além de permitir efeitos assimétricos de choques na variável de interesse, uma vantagem importante dos testes de raiz unitária quantílicos em relação aos testes padrão é que a abordagem QAR tem maior poder, conforme Koenker e Xiao (2004), através da inclusão de covariáveis quantílicas em todas as defasagens.

Por fim, para testar a hipótese de $\alpha(\tau)=1$, utiliza-se o teste $t$-stat proposto por Koenker e Xiao (2004):

$$
t_{n}(\tau)=\frac{f\left(\widehat{F^{-1}(\tau)}\right)}{\sqrt{\tau(1-\tau)}}\left(Y_{-1}^{\prime} M_{z} Y_{-1}\right)^{\frac{1}{2}}(\hat{\alpha}(\tau)-1)
$$

onde $f(u)$ e $F(u)$ são as funções de probabilidade e densidade cumulativa de $\epsilon_{t} . Y_{-1}$ é o vetor defasado da variável de interesse e $M_{Z}$ é a matriz de projeção no espaço ortogonal para $Z=\left(1, t, \Delta y_{t-1}, \Delta y_{t-2}, \ldots, \Delta y_{t-q+1}\right)$. Por fim, utilizam-se os resultados obtidos por Koenker e Xiao (2004) e Galvao (2009) para encontrar os valores críticos de $t_{n}(\tau)$ e estimar $f\left(F^{-1}(\tau)\right)$ seguindo a regra dada pelos mesmos autores.

No presente trabalho, considera-se o nível de significância de 5\% para os valores críticos. A regra de rejeição segue o padrão, se a estatística $t_{n}$ é numericamente menor que o valor crítico, então rejeita-se a hipótese nula de $\alpha(\tau)<1$.

No que diz respeito à função de densidade, o parâmetro $\hat{\beta}(\tau)$ é estimado para os quantis de interesse de acordo com a resolução de um problema de programação linear, ver Koenker e Bassett (1978). Assim, dado o vetor $\hat{\beta}(\tau)$, a função quantílica de $y_{t}$, condicionada aos valores passados da variável, pode ser definida como:

$$
Q_{y_{t}}\left(\tau_{i} \mid x\right)=x_{t}^{\prime} \hat{\beta}(\tau)
$$


enquanto a densidade condicional de $y_{t}$ pode ser estimada pela razão:

$$
\hat{f}_{y_{t}}\left(\tau \mid x_{t}\right)=\frac{\left(\tau_{i}-\tau_{i-1}\right)}{\hat{Q}_{r_{t}}\left(\tau_{i} \mid x_{t}\right)-\hat{Q}_{r_{t}}\left(\tau_{i-1} \mid x_{t}\right)}
$$

\subsection{Resultados Empíricos}

Os resultados empíricos apresentados nesta subseção utilizam duas proxies que buscam representar a incerteza presente na economia brasileira: i) Índice Economic Policy Uncertainty (EPU) proposto por Baker et al. (2016) com amostra referente ao período de 1991:01 a 2017:03; ${ }^{3}$ e ii) Indicador de Incerteza da Economia Brasil (IIE-Br/FGV), cuja amostra refere-se ao período 2000:01 a 2017:06. A escolha da defasagem no teste de raiz unitária foi automatizada pelo critério de seleção MAIC sugerido por Ng e Perron (2001).

Como destacam Bekiros et al. (2016) e Peng et al. (2017), a utilização de regressões quantílicas na análise da incerteza é importante devido à instabilidade estrutural desta variável, reportada empiricamente, o que torna a especificação linear inadequada e incapaz de considerar a potencial assimetria da incerteza na economia. Em outras palavras, o uso adequado de regressões quantílicas ocorre quando existem estimativas pontuais fora do intervalo de estimação OLS.

As Figuras 2 e 3 mostram as estimativas da Autoregressão Quantílica (QAR), para os quantis $\tau=\{0.05,0.10,0.15, \ldots, 0.90,0.95\}$, para ambas as medidas de incerteza, índice EPU e IIE-Br/FGV, respectivamente. A região cinza mostra o intervalo de confiança bootstrap para as estimativas pontuais quantílicas e a linha horizontal tracejada representa a estimativa a partir de uma regressão OLS padrão (na média) com intervalos a 95\% de confiança dados pelas linhas pontilhadas.

3 Todos os testes também foram simulados com amostra reduzida, 2000:01 a 2017:03. No entanto, os resultados se mantêm. Optamos pelo tamanho amostral maior por questão econométrica, pois regressões quantílicas são, em geral, aplicadas em cortes longos de forma que os quantis a serem ponderados não sofram de uma subespecificação, ou seja, não sejam afetados por poucos valores. 

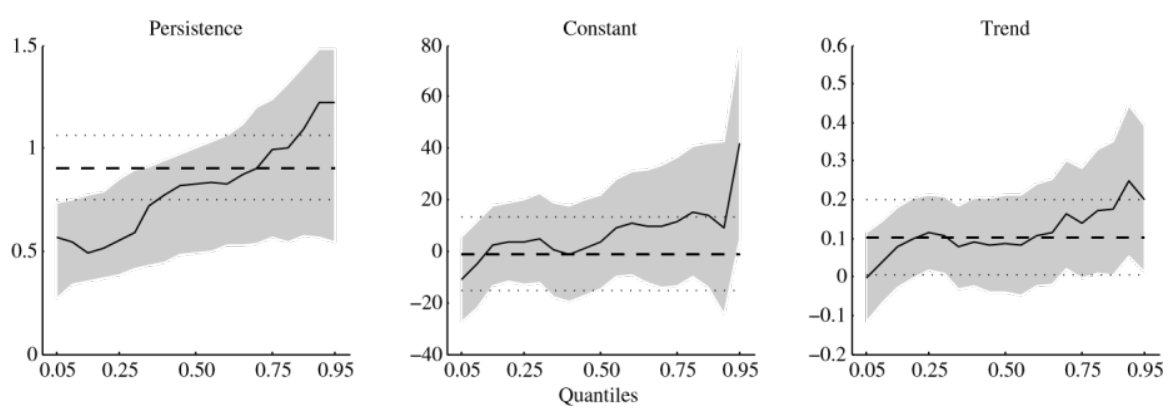

Figura 2 - Teste de Raiz Unitária Quantílico (Índice EPU)
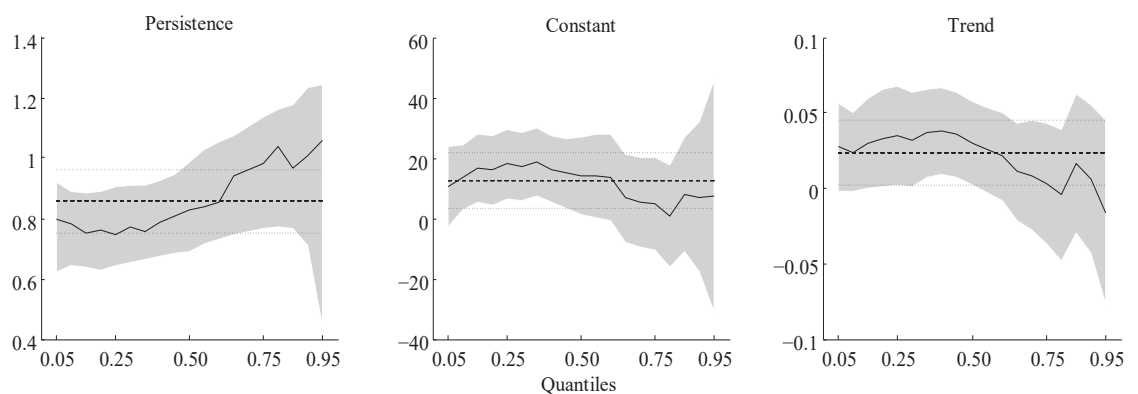

Figura 3 - Teste de Raiz Unitária Quantílico (IIE-Br/FGV)

Nota-se que os coeficientes autorregressivos do processo aparentam comportamento crescente ao longo dos quantis, com valores pontuais que oscilam de 0,5 até aproximadamente 1,2 na medida do índice EPU, e de 0,75 até 1,00 na segunda proxy IIE-Br/FGV. Ou seja, existem indícios de comportamentos assimétricos nas estimativas, em que os quantis condicionais mais baixos apresentam valores menores, mostrando uma tendência de reversão à média, e os quantis condicionais mais altos apresentam valores que alcançam (e até mesmo superam) a unidade, evidenciando comportam.̨ento não estacionário. Destaca-se que todos os intervalos de confiança estimados não contêm o valor zero, o que corroboram para significância estatística destes parâmetros. Contudo, o valor um está presente nos quantis superiores, a partir de 75\%, o que indica a possível presença de raiz unitária nos pontos da distribuição e, portanto, que existem persistências nas inovações. 
Além disso, reforçando a adequação do método, os pontos extremos da distribuição (tanto superiores quanto inferiores) aparentam fugir do intervalo de confiança baseado na estimação média (OLS). As constantes estimadas estão majoritariamente acima de zero, enquanto para a tendência quase todos os intervalos incluem zero, o que está em linha com a não rejeição da hipótese de raiz unitária na maior parte dos quantis.

Observa-se também que a maioria dos valores estimados para os coeficientes autorregressivos são inferiores à unidade, sugerindo estacionariedade global da incerteza. Assim, a incerteza no Brasil aparenta maior grau de persistência somente nos quantis condicionais superiores. Portanto, os resultados apresentados visualmente nas Figuras 2 e 3 indicam que a incerteza apresenta comportamento assimétrico nos diferentes quantis condicionais, ou seja, seu comportamento depende da localização da incerteza na distribuição condicional.

Esses resultados mostram importantes características presentes na dinâmica da incerteza brasileira, ainda não reveladas em exercícios empíricos anteriores. Observa-se que choques positivos de grande magnitude, como a recessão de 2008/2009, afetariam a série de incerteza permanentemente. No entanto, oscilações mais brandas trariam apenas efeitos transitórios.

De forma a validar estatisticamente as evidências observadas, aplica-se o teste de raiz unitária quantílico, cuja hipótese nula é . Todavia, antes utiliza-se o teste de raiz unitária ADF convencional às séries de incerteza. A defasagem utilizada no teste para ajuste do modelo de regressão ADF é selecionada por meio de minimização do Akaike Information Criterion (AIC), seguindo Maia e Cribari-Neto (2006) e Agiakloglou e Newbold (1996). Os modelos de regressão ADF foram ajustados podendo chegar a 15 e 14 defasagens para as séries EPU e IIE-Br/FGV, respectivamente.

O AIC indicou e para as respectivas regressões ADF. No índice EPU não foi possível rejeitar a hipótese nula de raiz unitária nem mesmo ao nível de $10 \%$ de significância. ${ }^{4}$ Já para o IIE-Br/FGV, o teste rejeita a hipótese de presença de raiz unitária ao nível de $5 \%$ de significância. ${ }^{5}$ O teste DFGLS corrobora os resultados anteriores ao não rejeitar a hipótese nula para

4 Estatística de 0.23 com p-valor de 0.99. Valores críticos: nível de 1\% de -3.99; nível de 5\% de -3.42; e nível de $10 \%$ de -3.13 .

5 Estatística de -3.57 com p-valor de 0.035. Valores críticos: nível de 1\% de -4.00; nível de 5\% de -3.43; e nível de $10 \%$ de -3.14 . 
o índice EPU e ao rejeitar a mesma ao nível de significância de 5\% para o IIE-Br/FGV. ${ }^{6}$

Entretanto, alguma quebra estrutural pode ter influenciado os resultados. Neste caso, aplica-se o teste de raiz unitária Zivot-Andrews que rejeita a hipótese nula ao nível de $1 \%$ de significância nas três alternativas de quebra estrutural testadas ${ }^{7}$ para o índice EPU. Enquanto que para a série IIE-Br/ FGV rejeita-se a presença de raiz unitária com quebra estrutural em dois casos, exceto para o caso de quebra em ambos, constante e tendência, que apenas rejeita a hipótese nula ao nível de $11 \%$ de significância ${ }^{8}$

Esses testes estatísticos podem gerar dúvidas quanto à dinâmica de incerteza no Brasil ser ou não um processo raiz unitária, tornando relevante a aplicação do teste de raiz unitária quantílico. Diante disso, busca-se investigar a dinâmica da incerteza no Brasil ao longo de sua distribuição condicional, aplicando a partir de agora testes de raiz unitária baseados em representações QAR para as duas proxies, índice EPU e IIE-Br/FGV.

A Tabela 1 apresenta as estimativas pontuais, as estatísticas e os valores críticos. Pode-se verificar a não rejeição da hipótese nula, nos quantis superiores a $35 \%$ na primeira proxy de incerteza (índice EPU) e nos quantis superiores a $55 \%$ na segunda amostra de incerteza (IIE-Br/FGV). Esses resultados corroboram os apresentados nas Figuras 2 e 3, ou seja, existem evidências de que, para as duas proxies analisadas, há assimetria no padrão de persistência. De modo geral, nos dois casos, é acrescido quando passa dos quantis mais baixos para os quantis mais altos. Esta característica é mais evidente no índice EPU. Note que não são poucos os quantis que apresentaram coeficiente estimado próximo da unidade. Assim, o teste permitiu verificar estatisticamente a possibilidade de um comportamento localmente estacionário e localmente explosivo.

6 EPU: Estatística de -0.75 , com os seguintes valores críticos: nível de $1 \%$ de -3.47 ; nível de 5\% de -2.91; e nível de 10\% de -2.60; IIE-Br/FGV: Estatística de -3.24, com os seguintes valores críticos: nível de $1 \%$ de -3.46 ; nível de $5 \%$ de -2.93 ; e nível de $10 \%$ de -2.64 .

7 EPU - Teste com quebra estrutural: i) constante: estatística t de -4.76, p-valor de 0.01 ; ii) tendência: estatística t de -6.90, p-valor de 0.00; constante e tendência: estatística t de -7.24, p-valor de 0.01.

8 IIE-Br/FGV - Teste com quebra estrutural: i) constante: estatística t de -4.65, p-valor de 0.00; ii) tendência: estatística t de -4.58 , p-valor de 0.01 ; constante e tendência: estatística t de -4.68 , p-valor de 0.11 . 
Tabela 1 - Indicadores de Incerteza - Teste de Raiz Unitária Quantílico

\begin{tabular}{ccccccc}
\hline & \multicolumn{3}{c}{ EPU: $1991: 01-2017: 03$} & \multicolumn{3}{c}{ IIEBr/FGV: 2000:01 - 2017:06 } \\
\hline Quantil & $\alpha(\tau)$ & tstatistic & Valor Crítico & $\alpha(\tau)$ & tstatistic & Valor Crítico \\
\hline 0,05 & $0,566^{*}$ & $-5,841$ & $-2,310$ & $0,797^{*}$ & $-4,397$ & $-2,310$ \\
0,10 & $0,543^{*}$ & $-5,344$ & $-2,310$ & $0,781^{*}$ & $-4,833$ & $-2,310$ \\
0,15 & $0,491^{*}$ & $-6,180$ & $-2,310$ & $0,752^{*}$ & $-5,523$ & $-2,761$ \\
0,20 & $0,513^{*}$ & $-5,744$ & $-2,324$ & $0,762^{*}$ & $-4,724$ & $-2,736$ \\
0,25 & $0,553^{*}$ & $-5,602$ & $-2,569$ & $0,748^{*}$ & $-4,841$ & $-2,886$ \\
0,30 & $0,587^{*}$ & $-4,813$ & $-2,564$ & $0,772^{*}$ & $-4,030$ & $-2,707$ \\
0,35 & $0,718^{*}$ & $-3,536$ & $-2,691$ & $0,755^{*}$ & $-4,268$ & $-2,949$ \\
0,40 & 0,776 & $-2,614$ & $-2,815$ & $0,785^{*}$ & $-3,638$ & $-2,729$ \\
0,45 & 0,815 & $-2,262$ & $-3,012$ & $0,809^{*}$ & $-3,174$ & $-2,851$ \\
0,50 & 0,828 & $-1,756$ & $-2,935$ & $0,830^{*}$ & $-3,152$ & $-2,923$ \\
0,55 & 0,830 & $-1,717$ & $-2,972$ & 0,840 & $-2,771$ & $-2,949$ \\
0,60 & 0,827 & $-1,668$ & $-3,018$ & 0,856 & $-2,475$ & $-3,038$ \\
0,65 & 0,874 & $-1,182$ & $-3,125$ & 0,940 & $-0,907$ & $-2,856$ \\
0,70 & 0,904 & $-0,759$ & $-3,101$ & 0,962 & $-0,492$ & $-3,066$ \\
0,75 & 0,994 & $-0,042$ & $-3,101$ & 0,983 & $-0,210$ & $-3,038$ \\
0,80 & 0,999 & $-0,006$ & $-3,161$ & 1,038 & 0,338 & $-3,011$ \\
0,85 & 1,093 & 0,494 & $-2,984$ & 0,966 & $-0,267$ & $-2,871$ \\
0,90 & 1,223 & 1,136 & $-2,911$ & 1,005 & 0,022 & $-3,276$ \\
0,95 & 1,219 & 1,638 & $-2,383$ & 1,060 & 0,257 & $-3,151$ \\
\hline
\end{tabular}

Nota: Estimativas pontuais, estatísticas e valores críticos para o nível de $5 \%$ de significância.

Se a estatística $\tau$ for menor que o valor crítico rejeita-se a hipótese nula de $\alpha(\tau)=1$ a $5 \%$.

Em outras palavras, corroborando com que foi analisado no modelo QAR, os resultados do teste de raiz unitária quantílico sugerem que a dinâmica de incerteza não apresenta um comportamento uniforme ao longo dos diferentes quantis condicionais do processo. De forma a reforçar os achados a respeito da presença da assimetria, na próxima subseção, apresenta-se outras estimativas a partir das funções densidades condicionais. 


\subsection{Funções Densidade e Probabilidade de Transição}

Nesta subseção trabalham-se as estimativas de funções densidade de forma similar ao que foi apresentado por Ferreira (2011), em relação à taxa de câmbio. Em outras palavras, investiga-se a assimetria presente nas proxies de incerteza, por meio das funções densidade condicionais; adicionalmente propõe-se um avanço relativo à interpretação destes dados, por meio da construção de uma matriz de probabilidades de transição quantílica.

Entretanto, antes de caminhar nessa direção é preciso selecionar os modelos a serem estimados por meio da abordagem quantílica. Opta-se, novamente, pelos modelos autorregressivos $A R(p)$ com p podendo tomar valor máximo igual a 8 defasagens. Os valores ótimos de p para cada variável resposta de incerteza foram selecionados através da minimização do Schwarz information criterion (SC). Para o índice EPU foi selecionado o modelo $A R(3)$, enquanto para a série IIE-Br/FGV foi selecionado o modelo $A R(1)$. Todas as autocorrelações residuais encontraram-se dentro do intervalo assintótico de 95\% de confiança, sugerindo que os modelos foram suficientes para filtrar a correlação serial em ambos os casos.

A captura da assimetria presente nas funções densidade estimadas é realizada por meio de duas etapas:

- Analisa-se a dispersão das distribuições, utilizando a amplitude condicional $\hat{R}\left(\widehat{y_{t}} \mid Q_{x}(\tau)\right)$ (diferença entre o maior e o menor valor da distribuição condicional) e o desvio padrão condicional $\hat{\sigma}\left(\widehat{y_{t}} \mid Q_{x}(\tau)\right)$; e

- Calculam-se as probabilidades de transição quantílica da série de incerteza e verifica-se sua disposição.

Como estima-se a densidade condicional aos quantis de $y_{t-1}$, pode-se calcular as probabilidades de transição para os demais intervalos quantílicos no período $t$. Basicamente, verifica-se se a densidade condicional ao quantil $\tau_{k}$ contém os valores dos demais intervalos quantílicos de interesse. Este cálculo permite analisar com maior profundidade a persistência das distribuições e a possibilidade de transição em casos de choques. Os resultados encontrados sinalizam uma considerável assimetria em ambas as proxies de incerteza brasileira, com comportamentos assimétricos e localmente 
persistentes. Esta característica desempenha papel fundamental na análise das políticas públicas, já que as ações governamentais baseadas em valores médios podem levar a resultados divergentes dos esperados e recuperações mais lentas do que o normal. Por exemplo, conforme Aastveit et al. (2013), choques de política monetária têm efeitos relativamente menores sobre a atividade econômica quando o nível de incerteza é elevado.

\subsection{1. Índice $E P U-M o d e l o ~ A R(3)$}

A partir do modelo $A R(3)$ selecionado, estimam-se as funções densidade condicionais utilizando os valores quantílicos da incerteza em $t-1$ e fixando as demais defasagens na mediana. Observe que quando se seleciona quantis específicos em $t-1$ pode-se analisar a assimetria da distribuição condicional ao longo desses valores, mas também inferir sobre a probabilidade da incerteza se deslocar no próximo período, compreendendo melhor sua persistência em situações distintas.

Ainda, a intuição de fixar as defasagens anteriores na mediana pode ser interpretado como a economia em uma situação de incerteza padrão em $t-3$ e $t-2$, mas que ao ser impactada por uma inovação em $t-1$ resulta nas probabilidades previstas para o estado em $t$.

Inicialmente, na Tabela 2, analisa-se a dispersão das distribuições em termos de desvio padrão condicional e amplitude condicional. Os resultados mostram que a dispersão e a amplitude são diferentes para períodos de baixa e alta incertezas. Além disso, o desvio padrão e a amplitude parecem dobrar do quantil 10\% até o $90 \%$. 
Tabela 2 - Modelo $A R(3)$ - (EPU) Dispersão e Amplitude

\begin{tabular}{ccc}
\hline$Q_{y_{t-1}}(\tau)$ & $\hat{R}\left(\widehat{y}_{t} \mid Q_{x}(\tau)\right)$ & $\hat{R}\left(\widehat{y_{t}} \mid Q_{x}(\tau)\right)$ \\
\hline $47,90 \tau=0,10$ & 32,96 & 198,87 \\
$63,36 \tau=0,20$ & 36,01 & 208,90 \\
$78,31 \tau=0,30$ & 39,03 & 218,66 \\
$89,67 \tau=0,40$ & 41,30 & 226,18 \\
$103,99_{\tau}=0,50$ & 44,18 & 235,55 \\
$118,91_{\tau}=0,60$ & 47,26 & 245,52 \\
$135,19_{\tau}=0,70$ & 50,54 & 256,26 \\
$154,30_{\tau}=0,80$ & 54,52 & 272,82 \\
$200,47_{\tau}=0,90$ & 64,07 & 312,46 \\
\hline
\end{tabular}

Buscando respostas mais robustas, na Tabela 3 , investiga-se em termos preditivos as possibilidades de mudanças quantílicas da incerteza. ${ }^{9}$ Pode-se observar que a probabilidade da incerteza se mover do quantil 10\% para o intervalo entre (90\%-100\%) é nula. O mesmo ocorre no sentido oposto, a probabilidade de que a incerteza se mova do quantil $90 \%$ para o intervalo entre (0\%-10\%), repentinamente, é nula.

Portanto, os resultados sugerem que na economia brasileira choques na incerteza não geram deslocamentos de estados extremos, isto é, de um estado de baixa incerteza para o estado de alta incerteza e vice-versa. Porém, pode-se notar que quando a incerteza se encontra acima da mediana em $t-1$, a probabilidade deste estado continuar nesta faixa superior (ou a soma dos intervalos de 50\% até 100\%) é sempre maior que 50\%. Além disso, quando a incerteza está no quantil 10\%, a probabilidade deste estado permanecer neste valor no período seguinte é inferior à probabilidade de que no quantil $90 \%$ a incerteza continue nessa faixa no período seguinte.

Logo, esses cálculos corroboram os resultados do teste de raiz unitária quantílico, quanto a persistência da incerteza nos quantis superiores, e apresentam um panorama mais robusto sobre a assimetria desta variável.

9 Note que os elementos de cada linha somam 1, pois dividem-se as distribuições condicionais em termos quantílicos. 
Tabela 3 - Modelo $A R(3)$ - (EPU) Transição

\begin{tabular}{ccccccccccc}
\hline \hline$Q_{y t-1}(\tau)$ & $P(0 / 10)$ & $P(10 / 20)$ & $P(20 / 30)$ & $P(30 / 40)$ & $P(40 / 50)$ & $P(50 / 60)$ & $P(60 / 70)$ & $P(70 / 80)$ & $P(80 / 90)$ & $P(90 / 100)$ \\
\hline$\tau=0,10$ & 0,158 & 0,182 & 0,187 & 0,160 & 0,114 & 0,077 & 0,051 & 0,035 & 0,034 & 0,000 \\
$\tau=0,20$ & 0,114 & 0,159 & 0,165 & 0,147 & 0,146 & 0,094 & 0,068 & 0,049 & 0,053 & 0,004 \\
$\tau=0,30$ & 0,082 & 0,132 & 0,155 & 0,124 & 0,159 & 0,113 & 0,081 & 0,066 & 0,07 & 0,015 \\
$\tau=0,40$ & 0,064 & 0,112 & 0,146 & 0,115 & 0,153 & 0,127 & 0,09 & 0,077 & 0,086 & 0,026 \\
$\tau=0,50$ & 0,046 & 0,091 & 0,132 & 0,109 & 0,141 & 0,137 & 0,102 & 0,088 & 0,109 & 0,042 \\
$\tau=0,60$ & 0,03 & 0,073 & 0,114 & 0,102 & 0,131 & 0,139 & 0,112 & 0,099 & 0,135 & 0,061 \\
$\tau=0,70$ & 0,017 & 0,058 & 0,097 & 0,092 & 0,123 & 0,134 & 0,121 & 0,107 & 0,159 & 0,087 \\
$\tau=0,80$ & 0,007 & 0,044 & 0,078 & 0,079 & 0,113 & 0,126 & 0,126 & 0,115 & 0,181 & 0,126 \\
$\tau=0,90$ & 0,000 & 0,015 & 0,0465 & 0,053 & 0,082 & 0,103 & 0,117 & 0,134 & 0,210 & 0,235 \\
\hline
\end{tabular}

As Figuras 4 e 5 reforçam toda a análise de desvios, amplitudes e probabilidades condicionais. Sugerem que a distribuição condicional da incerteza vai se deslocando para direita, tornando-se cada vez mais assimétrica positiva, engrossando a cauda direita e concentrando à esquerda. Ainda, conforme a Figura 5, a sobreposição mostra que as distribuições se tornam cada vez mais achatadas e com grande amplitude, logo, o crescimento da própria incerteza faz com que a variabilidade para os valores no período seguinte seja significativa e a frequência de valores baixos diminua.
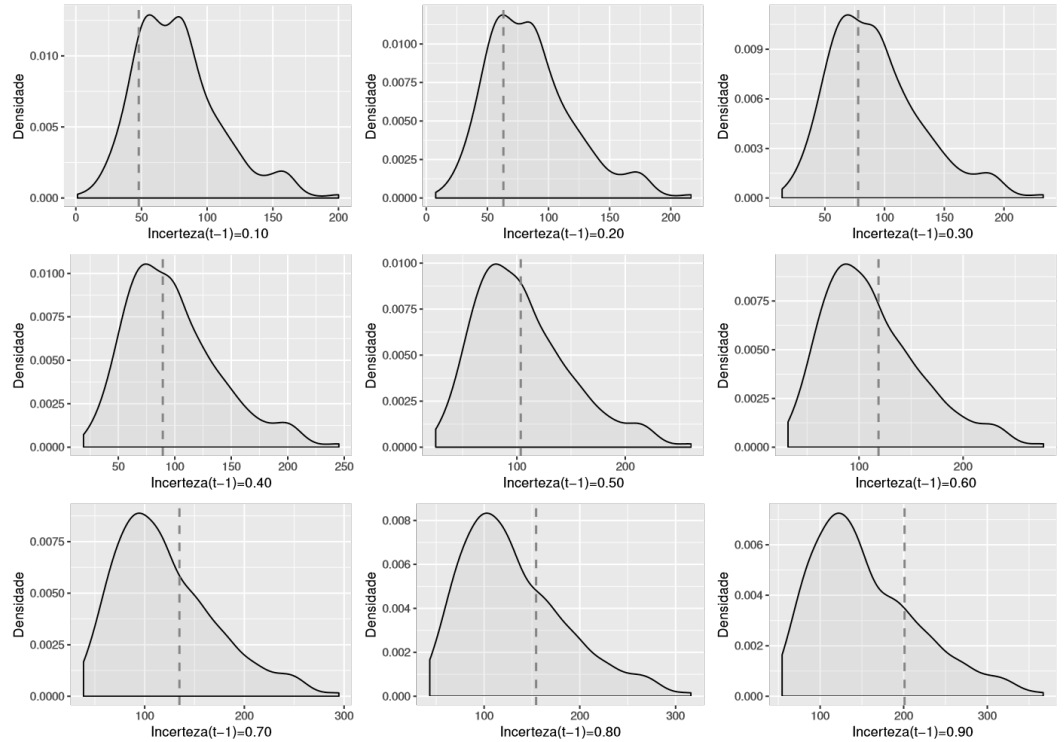

Figura 4 - Modelo $A R(3)$ - Densidades 


\subsubsection{IIE-Br/FGV-Modelo AR(1)}

Como simples critério de comparação e robustez de resultados, repetem-se os exercícios para a outra proxy de incerteza (IIE-Br/FGV) cujo modelo selecionado foi . A Tabela 4 também mostra que a dispersão e a amplitude são diferentes para períodos de baixa incerteza e períodos de grande incerteza, corroborando a presença de assimetria.

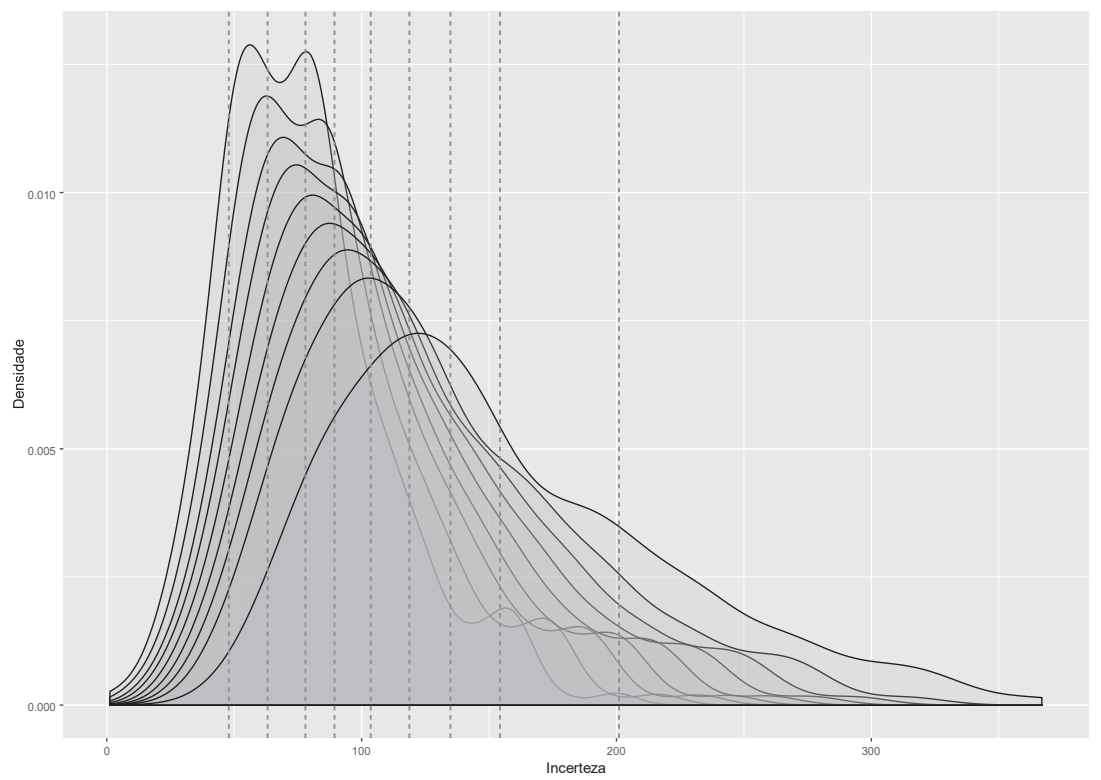

Figura 5 - Modelo $A R(1)$ - Densidades Sobrepostas

Contudo, nesta série de incerteza o desvio padrão aumenta, enquanto a amplitude diminui significativamente. Tais resultados apontam indícios de persistência nos momentos de altos níveis de incerteza. 
Tabela 4 - Modelo $A R(1)$ - (IIE-Br/FGV) Dispersão e Amplitude

\begin{tabular}{ccc}
\hline$Q_{y_{t-1}}(\tau)$ & $\hat{R}\left(\hat{y}_{t} \mid Q_{x}(\tau)\right)$ & $\hat{R}\left(\widehat{y}_{t} \mid Q_{x}(\tau)\right)$ \\
\hline $87,66 \tau=0,10$ & 33,73 & 174,04 \\
$90,60 \tau=0,20$ & 38,15 & 189,92 \\
$93,60 \tau=0,30$ & 42,45 & 212,86 \\
$95,14 \tau=0,40$ & 45,72 & 230,28 \\
$97,90 \tau=0,50$ & 49,87 & 252,24 \\
$101,11 \tau=0,60$ & 54,19 & 275,13 \\
$106,52 \tau=0,70$ & 58,93 & 300,10 \\
$115,64 \tau=0,80$ & 64,50 & 329,42 \\
$124,08 \tau=0,90$ & 77,98 & 400,23 \\
\hline
\end{tabular}

Já na Tabela 5 investigam-se, em termos preditivos, as possibilidades de mudanças quantílicas de nível de incerteza. Pode-se observar que a probabilidade da incerteza se mover do quantil $90 \%$ para o intervalo entre (0\%-10\%) é nula. Contudo, a probabilidade de que a incerteza se desloque do quantil $10 \%$ para o intervalo entre (90\%-100\%) é existente, mas de apenas aproximadamente $1 \%$. Ou seja, segundo a proxy IIE-Br/FGV, aparentemente na economia brasileira, choques positivos na incerteza podem se deslocar, mesmo a uma baixa probabilidade, de um extremo ao outro. Ainda, observa-se que quando a incerteza se encontra acima da mediana em $t-1$, a probabilidade desta situação continuar nessa faixa é maior, sempre superior a 70\%, corroborando de forma complementar os resultados assimétricos e de persistência superior do teste de raiz unitária.

As Figuras 6 e 7 também reforçam toda a análise de desvios, amplitudes e probabilidades condicionais para a proxy IIE-Br/FGV. A distribuição condicional da incerteza vai se deslocando para direita, engrossando cada vez mais a cauda direita. Finalmente, a sobreposição mostra que as distribuições se tornam cada vez mais concentradas e achatadas o que também está de acordo com as evidências de persistência. 
Tabela 5 - Modelo $A R(1)$ - Transição

\begin{tabular}{ccccccccccc}
\hline$Q_{y t-1}(\tau)$ & $P(0 / 10)$ & $P(10 / 20)$ & $P(20 / 30)$ & $P(30 / 40)$ & $P(40 / 50)$ & $P(50 / 60)$ & $P(60 / 70)$ & $P(70 / 80)$ & $P(80 / 90)$ & $P(90 / 400)$ \\
\hline$\tau=0,10$ & 0,372 & 0,273 & 0,185 & 0,036 & 0,050 & 0,040 & 0,020 & 0,005 & 0,005 & 0,010 \\
$\tau=0,20$ & 0,173 & 0,238 & 0,252 & 0,105 & 0,097 & 0,058 & 0,047 & 0,011 & 0,004 & 0,010 \\
$\tau=0,30$ & 0,063 & 0,144 & 0,240 & 0,124 & 0,190 & 0,111 & 0,083 & 0,027 & 0,005 & 0,010 \\
$\tau=0,40$ & 0,031 & 0,105 & 0,201 & 0,126 & 0,204 & 0,168 & 0,104 & 0,042 & 0,006 & 0,010 \\
$\tau=0,50$ & 0,000 & 0,051 & 0,127 & 0,101 & 0,208 & 0,219 & 0,190 & 0,080 & 0,009 & 0,010 \\
$\tau=0,60$ & 0,000 & 0,008 & 0,055 & 0,058 & 0,165 & 0,224 & 0,311 & 0,146 & 0,018 & 0,011 \\
$\tau=0,70$ & 0,000 & 0,000 & 0,003 & 0,012 & 0,047 & 0,142 & 0,340 & 0,369 & 0,067 & 0,016 \\
$\tau=0,80$ & 0,000 & 0,000 & 0,000 & 0,000 & 0,000 & 0,010 & 0,092 & 0,486 & 0,320 & 0,090 \\
$\tau=0,90$ & 0,000 & 0,000 & 0,000 & 0,000 & 0,000 & 0,000 & 0,007 & 0,201 & 0,413 & 0,377 \\
\hline
\end{tabular}
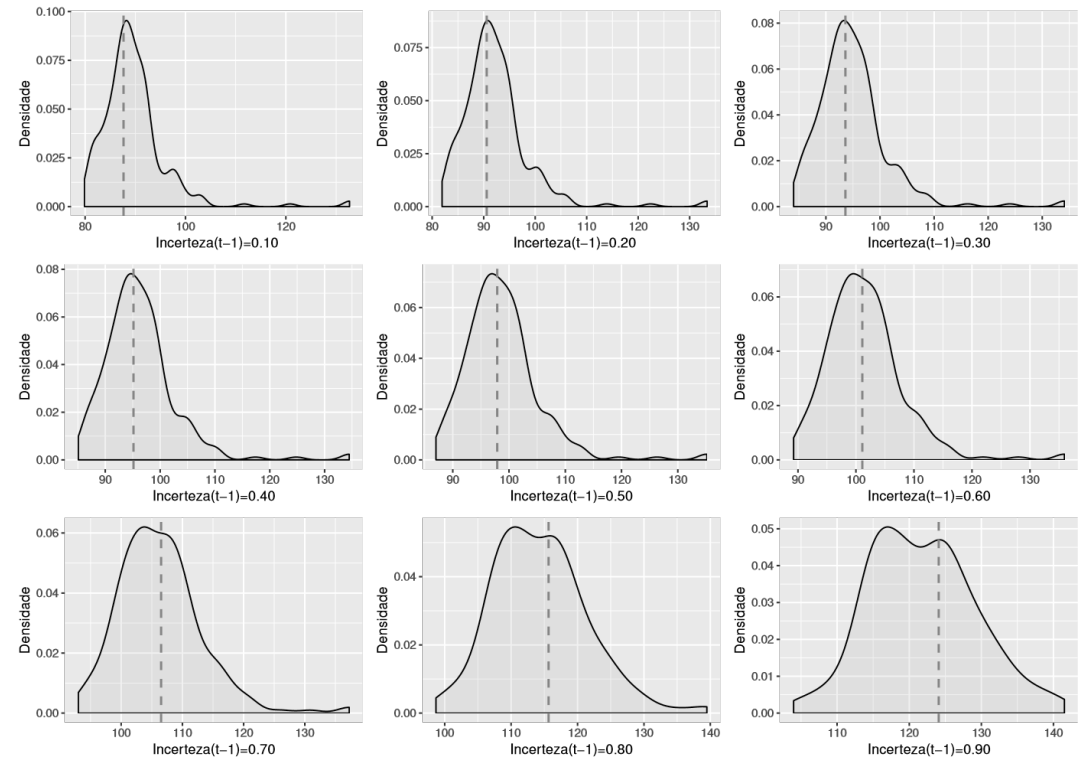

Figura 6 - Modelo $A R(1)$ - Densidades 
Em termos econômicos, os resultados apresentam pouca probabilidade, ou quase nula, de extremos estados de incerteza transitarem entre si no Brasil. Porém, pode-se notar que quando a incerteza se encontra acima da sua mediana em $t-1$, a probabilidade deste estado continuar nesta faixa superior é significativa.

Os resultados obtidos usando os índices de incerteza mais acessíveis ao público em geral, EPU e IIE-Br/FGV, não se alteraram ao repetir os mesmos exercícios utilizando os índices de incerteza estimados por Godeiro e Lima (2017) para horizontes de $\mathrm{h}=1,3$ e 12, onde a persistência também é verificada nos quantis superiores. ${ }^{10}$

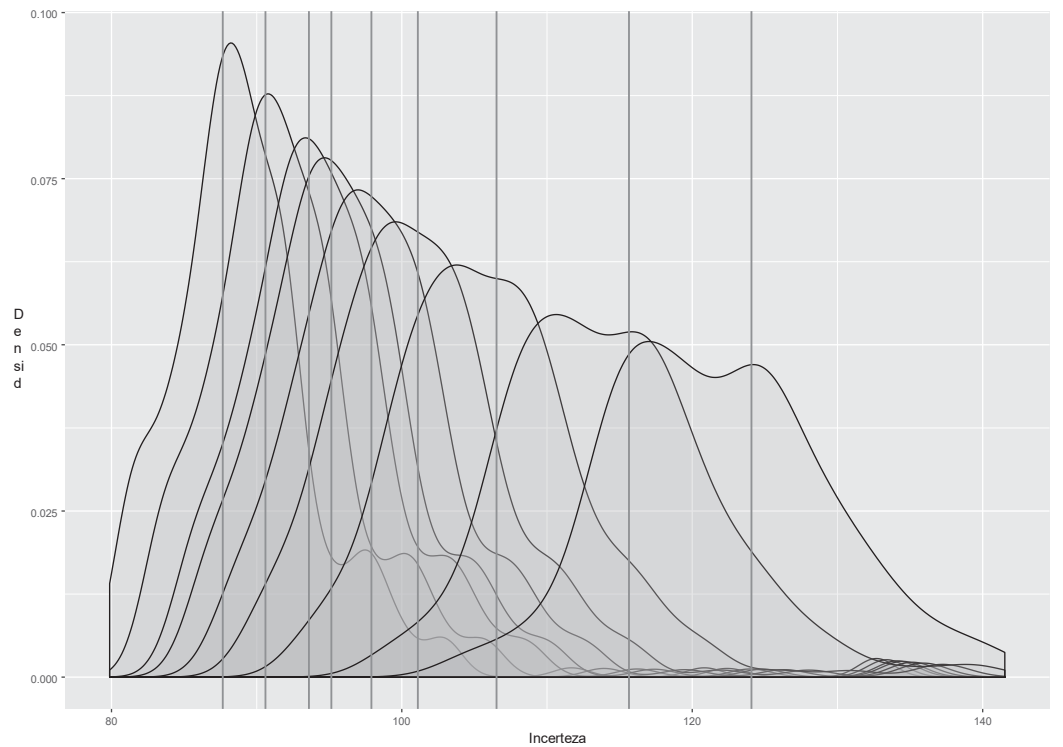

Figura 7 - Modelo $A R(1)$ - Densidades Sobrepostas

Tais resultados mostram que os aumentos de incerteza como os recentes em relação à economia brasileira não foram apenas choques pontuais, mas uma expansão mais duradoura, conforme se pode ver na Figura 1. Uma interpretação possível seria que, estando em um estado de menor incerteza,

\footnotetext{
${ }^{10}$ Os resultados foram omitidos por questão de espaço. Contudo, os mesmos podem ser requeridos aos autores.
} 
quando a economia é atingida por eventos pontuais que geram incerteza, esses eventos, além de aumentarem a incerteza, no primeiro momento, persistem na economia. Tal efeito acumulativo sobre a atividade econômica pode, portanto, ser negativamente relevante. Pode-se acrescentar que alguns dos fatores geradores da incerteza acumulativa estão interagindo entre si. Todavia, cabe sempre lembrar que, além das dificuldades de se construir um índice que capture a essência da incerteza econômica, é uma tarefa bastante complexa computar suas probabilidades de realização.

Diversos foram os eventos causadores de aumento da incerteza no Brasil. Segundo Ferreira et al. (2017), pode-se destacar: crise da Bolha da Internet (Abril/2000); atentado ao World Trade Center (Setembro/2001); eleições presidenciais (Outubro/2002); crise do Mensalão (Abril/2005); crise do subprime (Agosto/2007); quebra do Lehman Brothers (Setembro/2008); rebaixamento da nota de crédito dos EUA (Agosto/2011); crise da zona do euro (Agosto/2012); e as eleições presidenciais (Outubro/2014). Tais eventos fazem com que as empresas fiquem mais cautelosas, postergando contratações e investimentos enquanto aguardam por mais informações. Ainda, incertezas geram incremento na probabilidade de default, aumentando o prêmio de risco no mercado financeiro, bem como adiamento de consumo das famílias diante de maior dúvida a respeito da renda futura.

Em todos estes acontecimentos ver Figura 1 os indicadores de incerteza oscilam fortemente para cima frente a eventos adversos, e retornam a níveis mais baixos de forma lenta, comportamentos esses corroborados pelos exercícios empíricos aqui presentes. Contudo, uma exceção ocorre na crise norte americana de 2008/2009, em que o indicador IIE-Br aponta uma alteração rápida e brusca na incerteza (em termos quantílicos), do mês de junho de 2008 para o início de 2009. Esse evento, em específico, fica evidente na Figura lb, bem capturado pela matriz de transição estimada, já que no modelo para o IIE-Br existe uma baixa probabilidade desse movimento. Tal fato pode ser justificado pela simples amplitude das séries. O primeiro indicador (EPU) flutua em torno de 100 pontos e vai ligeiramente acima de 600. Enquanto o segundo (IIE-Br/FGV), a flutuação é próxima a 85 pontos e atinge valor máximo de 145 pontos, facilitando a transição entre extremos. 
Por fim, realizamos os mesmos exercícios para série de incerteza americana (EPU/USA), buscando investigar mesmo comportamento de persistência encontrado na economia brasileira. Os testes de raiz unitária quantílico indicam comportamentos explosivos nos quantis superiores e estacionariedade nos quantis inferiores. Ou seja, resultados similares aos brasileiros. Quanto a densidades, notamos que as distribuições se concentram à esquerda em baixos quantis, mas aparentam uma transição suave para cauda direita (reforçando o indicativo de persistência). O desvio padrão e a amplitude crescem pouco ao longo dos quantis, o que mostra um poder de previsibilidade mais homogêneo, independente do estado em que a incerteza se encontra. Além disso, a matriz de transição também apresenta resultados similares, mas com probabilidades maiores da mediana para frente.

\section{Considerações Finais}

O número de estudos sobre incerteza na economia tem aumentado, em parte devido às novas técnicas que permitem a construção de proxies adequadas para a incerteza, fundamentalmente não observável, com destaque à técnica de webscrapping, que permite extrair informações online e atualizadas, e que tem sido frequentemente utilizada na construção desses indicadores.

Nesse contexto, o presente estudo investigou a presença de efeitos assimétricos de choques na dinâmica da incerteza brasileira por meio de autorregressão quantílica no teste de raiz unitária, o que permite efeitos heterogêneos de choques de sinais e magnitudes diferentes. Para os dois indicadores de incerteza considerados, foi possível observar um comportamento assimétrico nas estimativas dos coeficientes autorregressivos, em que, para quantis condicionais mais baixos, ocorre uma tendência de reversão para a média, enquanto que para quantis condicionais mais altos, observa-se um comportamento não estacionário, por vezes, explosivo.

Portanto, choques que tendem a elevar o nível de incerteza, por exemplo, como a recessão de 2008/2009, podem ter efeitos permanentes na economia. Por outro lado, nas outras partes da distribuição condicional da incerteza, os resultados indicam que os choques apresentam efeitos transitórios. 
Resultados esses fortemente corroborados pelas análises apresentadas ao longo do estudo. Desse modo, os resultados empíricos demonstram uma importante característica presente na dinâmica da incerteza no Brasil, ainda não explorada.

Em termos econômicos, em níveis altos de incerteza, um choque adverso e significativo tende a reduzir a eficácia das ações políticas de recuperação econômica. Por exemplo, choques de política monetária podem ter efeitos relativamente menores sobre a atividade econômica quando o nível de incerteza é elevado, conforme observado por Aastveit et al. (2013). Nesse caso, cortes maiores de taxas de juros e taxações podem ser necessários para estimular a economia.

\section{Referências}

Aastveit, Knut Are, Gisle James Natvik e Sergio Sola. 2013. "Economic uncertainty and the effectiveness of monetary policy". Norges Bank Working Paper Series 17.

Agiakloglou, Christos e Paul Newbol. 1996. "The balance between size and power in dickey-fuller tests with data-dependent rules for the choice of truncation lag". Economics Letters 52(3): 229-234.

Arouri, Mohamed, Christophe Estay, Christophe Rault e David Roubaud. 2016.”Economic policy uncertainty and stock markets: Long-run evidence from the US". Finance Research Letters 18:136-141.

Bachmann, Ruediger, Steffen Elstner e Eric R. Sims. 2013.’Uncertainty and economic activity: Evidence from business survey data". American Economic Journal: Macroeconomics 5(2):217-249.

Baker, Scott Ross, Nicholas Bloom e Steven J. Davis. 2016.”Measuring economic policy uncertainty". The Quarterly Journal of Economics 131(4): 1593-1636.

Barboza, Ricardo de Menezes e Eduardo Zilberman. 2018. “Os Efeitos da Incerteza sobre a Atividade Economica no Brasil". Revista Brasileira de Economia 72: 1-18.

Beckmann, Joscha e Robert Czudaj. 2017. "Exchange rate expectations and economic policy uncertainty". European Journal of Political Economy 47: 148-162.

Bekiros, Stelios, Rangan Gupta e Anandamayee Majumdar. 2016. "Incorporating economic policy uncertainty in US equity premium models: A nonlinear predictability analysis”. Finance Research Letters 18: 291-296.

Bernal, Oscar, Jean-Yves Gnabo e Grégory Guilmin. 2016."Economic policy uncertainty and risk spillovers in the eurozone". Journal of International Money and Finance 65: 24-45.

Bernanke, Benjamin Shalom. 1983. “Irreversibility, uncertainty, and cyclical investment”. The Quarterly Journal of Economics 98(1): 85-106.

Bloom, Nicholas. 2009. "The impact of uncertainty shocks". Econometrica 77(3): 623-685.

Bloom, Nicholas, Max Floetotto, Nir Jaimovich, Itay Saporta-Eksten e Stephen J. Terry. 2012.’Really uncertainty business cycles". NBER Working Paper Series 18245. 
Bloom, Nicholas, M. Ayhan Kose e Marco E. Terrones. 2013. "Held back by uncertainty". Finance and Development, 38-41.

Bordo, Michael D. , John V. Duca e Christoffer Koch. 2016.'Economic policy uncertainty and the credit channel: Aggregate and bank level U.S. evidence over several decades". Journal of Financial Stability 26: 90-106.

Bredin, Don e Stilianos Fountas. 2007. "Is macroeconomic uncertainty bad for macroeconomic performance? evidence from five Asian countries". Centre for Financial Markets Working Paper Series 04.

Choudhry, Taufiq. 2003. "Stock market volatility and the US consumer expenditure". Journal of Macroeconomics 25:367-385.

Costa Filho, Adonias Evaristo da. 2014.'Incerteza e atividade econômica no brasil". Economia Aplicada 18: 421-453.

Dakhlaoui, Imen e Chaker Aloui. 2016. "The interactive relationship between the U.S. economic policy uncertainty and BRIC stock markets". International Economics 146: 141-157.

Denis, Stephanie e Prakash Kannan. 2013.’The impact of uncertainty shocks on the UK economy". IMF Working Paper 66.

Dixit, Avinash e Robert Pindyck. 1994. Investment under Uncertainty. [s.l.]: Princeton University Press.

Ejarque, João Miguel. 2009. "Uncertainty, irreversibility, durable consumption and the great depression”. Economica 76(303): 574-587.

Ferreira, Mauro Sayar. 2011. "Capturing asymmetry in real exchange rate with quantile autoregression”. Applied Economics 43: 327-340.

Ferreira, Pedro Costa, Ingrid C. L. de Oliveira, Lucas Farias Lima e Anna C. S. Barros. 2017. "Medindo a incerteza econômica no brasil". IBRE: Texto para Discussão, Junho, 1-22.

Galvao, Antonio F. 2009. "Unit root quantile autoregression testing using covariates". Journal of Econometrics 152(2): 165-178.

Gilchrist, Simon, Jae W. Sim e Egon Zakrajšek. 2014."Uncertainty, financial frictions, and investment dynamics". NBER Working Paper Series, 200384.

Godeiro, Lucas Lúcio e Luiz Renato Régis de Oliveira Lima. 2017. "Medindo incerteza macroeconômica para o brasil". Economia Aplicada 21(2): 311-334.

Istrefi, Klodiana e Anamaria Piloiu. 2015. "Economic policy uncertainty and inflation expectations". Banque de France Working Paper 511.

Jurado, Kyle, Sydney C. Ludvigson e Serena Ng. 2015. "Measuring uncertainty". American Economic Review 105(3): 1177-1216.

Koenker, Roger e Zhijie Xiao. 2004."Unit root quantile autoregression inference". Journal of the American Statistical Association 99: 775-787.

Koenker, Roger e Gilbert Basset. 1978. "Regression quantiles". Econometrica 46(1): 33-50.

Leduc, Sylvain e Zheng Liu. 2016. "Uncertainty shocks are aggregate demand shocks". Journal of Monetary Economics 82:20-35.

Liu, Li e Tao Zhang. 2015. "Economic policy uncertainty and stock market volatility". Finance Research Letters 15: 99-105.

Maia, André Luis Santiago e Francisco Cribari-Neto. 2006. "Dinâmica inflacionária brasileira: resultados de auto-regressão quantílica”. Revista Brasileira de Economia 60(2): 153-165.

Menegatti, Mario. 2010. "Uncertainty and consumption: New evidence in OCDE countries". Bulletin of Economic Research 62(3): 227-242.

Ng, Serena e Pierre Perron. 2001. "Lag length selection and the construction of unit root tests with good size and power". Econometrica 69(6): 1519-1554. 
Peng, Guo, Zhu Huiming e You Wanhai. 2017. “Asymmetric dependence between economic policy uncertainty and stock market returns in G7 and BRIC: A quantile regression approach". Finance Research Letters, 1-8.

Pereira, Rodrigo M. 2001. "Investment and uncertainty in a quadratic adjustment cost model: Evidence from brazil". Revista Brasileira de Economia 55(2): 283-311.

Popp, Aaron e Fang Zhang. 2016. "The macroeconomics effects of uncertainty shocks: The role of the financial channel". Journal of Economic Dynamics and Control 69: 319- 349.

Raunig, Burkhard e Johann Scharler. 2011. "Stock market volatility, consumption and investment: An evaluation of the uncertainty hypothesis using post-war U.S. data". Austrian Central Bank Working Paper Series, 168.

Romer, Christina D. 1990. "The great crash and the onset of the great depression". The Quarterly Journal of Economics 105(3): 597-624.

Silva Filho, Tito Nicias Teixeira. 2007. "Is the investment-uncertainty link really elusive? the harmful effects of inflation uncertainty in brazil”. Banco Central do Brasil, Working Paper Series 157.

Scotti, Chiara. 2013. "Surprise and uncertainty indexes: real-time aggregation of real-activity macro surprises". FRB International Finance Discussion Paper 1093. 